\title{
Effect of Introducing the Jordanian Common Rue (Ruta chalepensis L.) on Liver Enzymes and Lipid Peroxidation in Adult Male Sprague Dawley Rats Toxified With Paracetamol
}

\author{
Dana N. Abdelrahim ${ }^{1}$, Hamed R. Takruri ${ }^{1} \&$ Khalid M. Al-Ismail ${ }^{1}$ \\ ${ }^{1}$ Department of Nutrition and Food Technology, Faculty of Agriculture, The University of Jordan, Amman, Jordan \\ Correspondence: Hamed R. Takruri, Faculty of Agriculture, The University of Jordan, P.O. Box 11942, Amman, \\ Jordan. Tel: 962-6-5355-000 Ext. 22410. E-mail: htakruri@ju.edu.jo
}

Received: February 2, 2020

Accepted: March 3, $2020 \quad$ Online Published: March 15, 2020

doi:10.5539/jas.v12n4p298

URL: https://doi.org/10.5539/jas.v12n4p298

\begin{abstract}
This study aimed to determine the effect of Ruta chalepensis L. plant on liver enzymes, liver weight and lipid peroxidation using rats toxified with paracetamol. An animal experiment was conducted using five groups of Sprague Dawley rats, 9 rats each. The groups were fed: Normal diet, high cholesterol diet, with or without the plant or the liver toxicant paracetamol (PCM). The experiment lasted six weeks; at the end of the sixth week; a single dose of $3 \mathrm{~g}$ paracetamol $/ \mathrm{kg}$ body weight was given for rats of two groups, then blood and liver samples were collected. The hepatoprotective effect of the plant was evaluated using aspartate aminotransferase (AST), alanine aminotransferase (ALT) and total bilirubin (TBL) levels as indicators. This study finds that the groups to which plant and PCM were given had significantly lower MDA levels in comparison with other groups that didn't receive plant before PCM toxification. Tested liver enzymes levels were significantly $(\mathrm{P}<0.05)$ lowered by the introduction of plant to the diet. Introducing PCM without ingestion of plant in the diet significantly $(\mathrm{P}<0.05)$ increased the rats absolute liver weight. It is concluded that the use of Ruta chalepensis L. plant significantly lowered hepatic toxicity as indicated by the liver enzymes levels. Also, the plant lowered the MDA level and liver weight. The ingestion of the plant can be significantly protective against hepatic injury.
\end{abstract}

Keywords: alanine aminotransferase, aspartate aminotransferase, bilirubin, common rue, paracetamol, Ruta chalepensis L.

\section{Introduction}

\subsection{Ruta chalepensis L. in Jordan}

Flora of Jordan is highly diversified in its number of vascular, flowering plants. It was reported that 2500 species exist in Jordan (Oran \& Al-Isai, 2015). Many of these plants are edible and grow as wild and are rich in nutrients including vitamins and minerals and trace elements; therefore, they complement staple foods towards a balanced diet (Dogan, Ugulu, \& Durkan, 2013). Among the edible plants which are common in Jordan is common rue (Ruta chalepensis L.) (Afifi \& Abu-Irmaileh, 2000).

The plant is an ornamental, aromatic, culinary and medicinal plant, grown in the wild and can be cultivated in gardens (Abbas et al., 2017). It belongs to the Rutaceae family. It is a hard, evergreen shrub of up to one-meter height with a characteristic grayish color and a sharp pleasant odor (Al-Qudah et al., 2015). It is endemic in the Mediterranean region and has been introduced to and cultivated in many parts of the world because of its medicinal properties. A total of 45 compounds were detected in its leaves. These include alkaloids, flavonoids, lignans, terpenes, and coumarins (Kong et al., 1989) which represent approximately $93 \%$ of the total quantum (Perpera et al., 2017). Among the claims for using the plant are anti-inflammatory (Raghav, Gupta, Agrawal, Goswami, \& Das, 2006), anti-tumor (Preethi, Kuttan, \& Kuttan, 2006), anti-nociceptive (Atta \& Alkofahi, 1998), antirheumatic (Khouri \& El-Akawi, 2005), antimicrobial (Ivanova, Mikhova, Najdenski, Tsvetkova, \& Kostova, 2005), anti-carcinogenic, antimutagenic and cardioprotective effects (Volf, Ignat, Neamtu, \& Popa, 2013).

Antioxidants are compounds that can delay or inhibit the oxidation of lipids or other molecules by inhibiting the initiation or propagation of oxidizing chain reactions (Volf et al., 2013). Nowadays, antioxidant agents of natural origin have attracted special interest because they can protect the human body from free radicals, due to its high content of polyphenolic compounds (Pandey \& Rizvi, 2009). Accordingly, antioxidants can protect the body from 
reactive oxygen species (ROS) that damages cells and prevent carcinogenesis by scavenging them. In addition, they protect people from developing many diseases (Terkmane et al., 2017).

The imbalance between antioxidant production and free radicals formation can induce lipid peroxidation, DNA fragmentation, and protein oxidation (Terkmane et al., 2017). The reaction of ROS with lipids that contain carbon-carbon double bonds, especially polyunsaturated fatty acids (PUFA), is generally known as "lipid peroxidation" (Tsikas, 2017). This process in PUFAs results in lipid peroxyl radicals and hydroperoxides including malondialdehyde (Ayala, Muñoz, \& Argüelles, 2014). Malondialdehyde (MDA) is the main end-product of lipid peroxidation. It is considered as a biomarker of oxygen free radicals and has the potential to evaluate the extent of oxidative injury and to predict the potential efficiency of therapeutic strategies aimed at restricting the oxidative stress (L. Wang, Sun, Yi, X. Wang, \& Ju, 2012). The thiobarbituric acid reacting substances test (TBARS) is used for MDA determination. This test is based on the reactivity of thiobarbituric acid (TBA) toward MDA to yield an intensely colored chromogen fluorescent red adduct (Ayala et al., 2014).

\subsection{Liver Toxicity}

The liver plays a major role in the metabolism and detoxification of drugs and the acquisition of homeostasis in the body. Accordingly, liver contributes to decreasing stress caused by ROS that leads to organ malfunctions and decreased organ activities (Singh, Cho, \& Upadhyay, 2015). Blood tests used for monitoring the status of the liver are a standard part of medical care, particularly for individuals who either have underlying liver disease or are taking medications that can cause hepatotoxicity; the most used blood tests are aspartate aminotransferase (AST), alanine aminotransferase (ALT) and total bilirubin (TBL) (Pollock et al., 2012).

Assessing the pattern and degree of elevation in aminotransferases can help to suggest the cause of liver injury. Processes leading to necrosis of hepatocytes or damage to the hepatocyte cell membrane with increased permeability result in the release of AST and ALT into the blood (Woreta \& Alqahtani, 2014). AST is less sensitive and specific for the liver than ALT (Woreta \& Alqahtani, 2014). ALT is found in the highest concentration in hepatocytes and in very low concentrations in any other tissue. Thus, ALT is a more specific marker for liver injury (Woreta \& Alqahtani, 2014).

Bilirubin is a catabolic product of the heme metabolism that is formed by the degradation of heme component of hemoglobin and is released during the breakdown of red blood cells (Nam et al., 2018). Hyperbilirubinemia may occur as a result of both hepatocellular and cholestatic injury (Woreta \& Alqahtani, 2014).

Drug-induced liver injury is a relatively common cause of acute liver disease and leads to mortality of around $10 \%$ of cases. Extensive research on drug-induced hepatic cell damage worldwide has been done in the past and is also an area of major concern at present since hepatotoxicity due to these drugs, when it becomes terminal, results in malnutrition, organ dysfunction, and death (Singh et al., 2015). Among the drugs that cause hepatotoxicity is paracetamol (Hinson, Reid, McCullough, \& James, 2004). The objective of this study was to determine the effect of Ruta chalepensis L. plant on liver enzymes, liver weight and lipid peroxidation in rats toxified with paracetamol.

\section{Materials and Methods}

\subsection{Plant Collection, Drying and Grinding}

The fresh common rue was collected from Ajloun mountains (North Jordan) from March to April 2018 (the season of their growth). The leaves, flowers and the top 10-15 cm of the fresh stems aerial parts were used in the study. It was shade-dried at room temperature for approximately three weeks with occasional flipping. The dry plant was powdered mechanically to an average diameter of $0.4 \mathrm{~mm}$ using a high-efficiency food grinder (CHAORAN, 220V, $1700 \mathrm{~W}$, China) and sieved to remove the large particles.

\subsection{Experimental Animals}

Forty five adult male rats at eight weeks of age, weighing (200-250 g) were obtained from the Animal Unit at Jordan University of Science and Technology (Irbid, Jordan) and transferred to the Animal Unit at the Department of Nutrition and Food Technology/Faculty of Agriculture/The University of Jordan. Rats were weighed and kept for a week for acclimatization before starting the experiment. The rats were fed standard diet served in glass jars with open access to tap water ad libitum. Then rats were housed individually in plastic cages under controlled conditions including temperature $\left(23 \pm 2{ }^{\circ} \mathrm{C}\right)$, humidity $(49 \pm 5 \%)$, and hygienic conditions in a ventilated room that is maintained at 12-hr light/dark cycle. After acclimatization, rats were weighed and randomized into five groups, nine rats each, according to their initial body weight. The groups regarding dietary treatment were:

Group 1: Normal Diet; 
Group 2: High cholesterol diet (HCD);

Group 3: High cholesterol diet (HCD) with 2.5\% plant;

Group 4: High cholesterol diet (HCD) that received paracetamol dose without plant;

Group 5: High cholesterol diet (HCD) that received paracetamol dose with 2.5\% plant.

Experimental diet mixtures were prepared according to the guidelines of the American Institute of Nutrition 1993 for adult animals (AIN-93M) recommended by Reeves (1997). The synthetic antioxidant tertiary butylhydroquinone (TBHQ) was added to prevent the oxidation of the high polyunsaturated fatty acids in foods (10 mg for each $10 \mathrm{~g}$ fat). The amount of corn starch, egg white and soybean oil in the AIN-93M diet were modified based on the proximate analysis of the plant sample to establish approximately an isocaloric diet. A modification was done by using egg white as a source of protein instead of casein. Therefore, biotin premix was added (10 g/kg Diet) (Reeves, 1997).

\subsection{Preparation of Paracetamol Suspension and Inducing Liver Toxicity}

In this experiment paracetamol (PCM) was used in a concentration of $3 \mathrm{~g} / \mathrm{kg}$ body weight. A single dose of PCM in syrup suspension was given to all rats in Groups 4 and 5 only. The rats in those two groups were weighed on the same day of the toxification process to calculate the accurate dose needed. The dose was introduced to the rats via oral gavage needle before 48 hours of dissection.

\subsection{Animal Dissection and Blood Samples Collection}

After six weeks of the experiment, the rats were fasted overnight. In the morning, rats were anesthetized by chloroform, and blood samples were collected from the right ventricle of the heart by a medical syringe and transferred into plain tubes with gel. The blood samples were left for 30 minutes to clot. After clotting, blood samples were centrifuged at $3500 \mathrm{rpm}$ for 8 minutes (HERMLE Z200A, LaborTechnik, Wehingen, Germany). Finally, each serum sample was separated into three Eppendorf tubes and preserved at $-18{ }^{\circ} \mathrm{C}$ until analyzed. The whole livers were collected, washed with $0.9 \%$ normal saline and weighed.

\subsection{Lipid Peroxidation (MDA) Assay}

Serum malondialdehyde (MDA) concentration was determined using thiobarbituric acid reactive substance assay (TBARS) based on the procedure described by Esterbauer and Cheeseman (1990). For this purpose, $0.5 \mathrm{ml}$ of the serum sample was mixed with $2.5 \mathrm{ml}$ of $10 \%$ trichloroacetic acid (TCA) solution in a centrifuge tube, and then the tube was placed in a boiling water bath for 15 minutes. After that, tubes were cooled by cold water and then centrifuged at $3000 \mathrm{rpm}$ for 10 minutes (HERMLE Z200A, Wehingen, Germany). Then $2 \mathrm{ml}$ of the aliquot supernatant was added to $1 \mathrm{ml}$ of the $0.67 \%$ thiobarbituric acid (TBA) solution in another test tube. The tube was placed again in a boiling water bath for 15 minutes and finally cooled in tap water. The absorbance was measured using a spectrophotometer at $532 \mathrm{~nm}$ against blank. The results were expressed as MDA equivalent. Samples were analyzed in triplicate.

\subsection{Liver Function Tests Assay}

Aspartate aminotransferase enzyme (AST), alanine aminotransferase enzyme (ALT) and total bilirubin (TBL) were done in Mega Lab which is an accredited private Medical Laboratory (Amman, Jordan). An automated clinical analyzer (ARCHITECT plus, Serial number: i1SR56522, Abbott, Germany) was used for the analysis.

\subsection{Statistical Analysis}

Statistical analysis of the data was performed using a statistical package for the social science software (SPSS) version 24. Data were expressed as mean \pm standard error of the mean (SEM) and the levels of significance were at $(\mathrm{P}<0.05)$. Analysis of variance (ANOVA) followed by Least Significance Difference (LSD) test was used to determine any significant differences among the variable means of the study groups.

\section{Results}

\subsection{Absolute and Relative Liver Weight}

Table 1 shows the mean and the standard error of the mean (SEM) for the absolute liver weight (g) and relative liver weight (g/g BW) for the studied groups. Absolute liver weight for the control group (normal diet group) had the lowest weight $(8.9 \pm 0.3)$ and it was significantly different $(\mathrm{P}<0.05)$ from all other groups. Adding PCM without plant (Group 4) resulted in significantly higher liver weight (15.8 \pm 0.9$)$ in comparison with all other groups; $8.9 \pm 0.3,12.2 \pm 0.4,13.5 \pm 0.6$ and $12.6 \pm 0.6$ for Groups $1,2,3$ and 5 respectively. 
Regarding relative liver weight, the normal diet group (Group 1) (3.2 \pm 0.1$)$ had significantly $(\mathrm{P}<0.05)$ the lowest relative liver weight among all of the groups. The addition of PCM in Group 4 (4.8 \pm 0.2$)$ and Group $5(4.5 \pm 0.2)$ resulted in significantly $(\mathrm{P}<0.05)$ higher relative liver weight as compared with relative liver weight of Group 2 (HCD) (3.9 \pm 0.1$)$ and Group 1 (normal diet) to which no PCM was added.

Table 1. Absolute liver weight and relative liver weight among experimental groups*

\begin{tabular}{lll}
\hline Group Description & Absolute Liver Weight (g) & Relative Liver Weight (g) ** \\
\hline 1. Normal AIN Diet & $8.9 \pm 0.3^{\mathrm{a}}$ & $3.2 \pm 0.1^{\mathrm{a}}$ \\
2. HCD w/o plant w/o PCM & $12.2 \pm 0.4^{\mathrm{b}}$ & $3.9 \pm 0.1^{\mathrm{b}}$ \\
3. HCD w plant w/o PCM & $13.5 \pm 0.6^{\mathrm{b}}$ & $4.3 \pm 0.1^{\mathrm{bc}}$ \\
4. HCD w/o plant w PCM & $15.8 \pm 0.9^{\mathrm{c}}$ & $4.8 \pm 0.2^{\mathrm{d}}$ \\
5. HCD w plant w PCM & $12.6 \pm 0.6^{\mathrm{b}}$ & $4.5 \pm 0.2^{\mathrm{cd}}$ \\
\hline
\end{tabular}

Note. HCD: high cholesterol diet, w: with, w/o: without, PCM: paracetamol, B.W.: body weight.

* Values are expressed as Mean \pm SEM. Values with different superscription within the same column are significantly different at $P<0.05$. Different letters in the column indicate significant difference, ranks were based on total mean differences.

** Relative Liver Weight $=$ Liver weight $(\mathrm{g}) /$ Body weight $\times 100 \%$.

\subsection{Lipid Peroxidation (MDA) Assay}

Table 2 shows the mean and the standard error of the mean for MDA levels in the studied groups. MDA values were calculated as nmol $\mathrm{MDA} / \mathrm{ml}$. MDA for group 5 to which plant and PCM were added $(9.4 \pm 0.7)$ was significantly lower $(\mathrm{P}<0.05)$ than all other experimental groups in which MDA values were not significantly different from each other.

Table 2. Serum malondialdehyde concentration (MDA) among experimental groups*

\begin{tabular}{ll}
\hline Group Description & MDA Test (nmol/ml) \\
\hline 1. Normal AIN Diet & $12.9 \pm 0.6^{\mathrm{b}}$ \\
2. HCD w/o plant w/o PCM & $13.1 \pm 0.6^{\mathrm{b}}$ \\
3. HCD w plant w/o PCM & $13.6 \pm 0.6^{\mathrm{b}}$ \\
4. HCD w/o plant w PCM & $13.8 \pm 0.7^{\mathrm{b}}$ \\
5. HCD w plant w PCM & $9.4 \pm 0.7^{\mathrm{a}}$ \\
\hline
\end{tabular}

Note. HCD: high cholesterol diet, PCM: paracetamol, MDA: malondialdehyde

*Values are expressed as Mean \pm SEM. Values with different superscription within the same column are significantly different at $P<0.05$. Different letters in the column indicate a significant difference.

\subsection{Liver Function Tests}

Table 3 shows the means of serum levels of aspartate aminotransferase (AST), alanine aminotransferase (ALT) and total bilirubin (TBL) among the experimental groups. Regarding AST, the addition of PCM in both Group 4 (38736.7 \pm 10740.4$)$ and Group 5 (14062.2 \pm 960.6$)$ remarkably increased the AST values as compared with the groups with no PCM addition; (75.4 $\pm 7.8,84.0 \pm 11.8,75.7 \pm 2.2$, for Groups 1,2 and 3 respectively). The ingestion of the plant within the diet as in Group 5 significantly lowered the effect of PCM toxicity on AST values as compared with Group 4 (to which no plant was added).

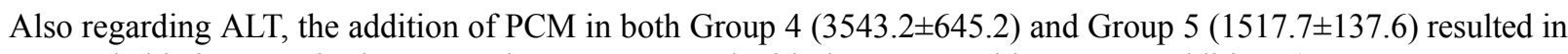
a remarkable increase in the ALT values as compared with the groups with no PCM addition; $(35.1 \pm 3.1,30.7 \pm 1.8$, $27.4 \pm 1.6$ for Groups 1, 2 and 3 respectively). The ingestion of plant within the diet as in Group 5 was associated with a significant decrease in ALT values as compared with Group 4. 
Table 3. Aspartate aminotransferase (AST), alanine aminotransferase (ALT) and total bilirubin (TBL) serum levels among experimental groups*

\begin{tabular}{llll}
\hline Group Description & AST (U/L) & ALT (U/L) & TBL (umol/l) \\
\hline 1. Normal AIN Diet & $75.4 \pm 7.8^{\mathrm{a}}$ & $35.1 \pm 3.1^{\mathrm{a}}$ & $1.7 \pm 0.01^{\mathrm{a}}$ \\
2. HCD w/o plant w/o PCM & $84.0 \pm 11.8^{\mathrm{a}}$ & $30.7 \pm 1.8^{\mathrm{a}}$ & $1.7 \pm 0.01^{\mathrm{a}}$ \\
3. HCD w plant w/o PCM & $75.7 \pm 2.2^{\mathrm{a}}$ & $27.4 \pm 1.6^{\mathrm{a}}$ & $1.7 \pm 0.0^{\mathrm{a}}$ \\
4. HCD w/o plant w PCM & $38736.7 \pm 10740.4^{\mathrm{c}}$ & $3543.2 \pm 645.2^{\mathrm{c}}$ & $8.1 \pm 1.7^{\mathrm{c}}$ \\
5. HCD w plant w PCM & $14062.2 \pm 960.6^{\mathrm{b}}$ & $1517.7 \pm 137.6^{\mathrm{b}}$ & $4.7 \pm 0.4^{\mathrm{b}}$ \\
\hline
\end{tabular}

Note. * Values are expressed as Mean \pm SEM. Values with different superscription within the same column are significantly different at $P<0.05$. Different letters in columns indicate significant difference.

HCD: high cholesterol diet, PCM: paracetamol, AST: aspartate aminotransferase, ALT: alanine aminotransferase, TBL: total bilirubin.

On the other hand, the addition of PCM in both Group $4(8.1 \pm 1.7)$ and Group 5 (4.7 \pm 0.4$)$ led to a remarkable increase in the TBL values as compared with the groups with no PCM addition; $1.7 \pm 0.01,1.7 \pm 0.01,1.7 \pm 0.0$ for Groups 1, 2 and 3 respectively. The ingestion of the plant within the diet as in Group 5 was associated with a significant decrease in TBL values as compared with Group 4 ( $8.1 \pm 1.7$ and $4.7 \pm 0.4$ respectively).

\section{Discussion}

Dietary fat and type of fat can affect health. Lipid oxidation occurs during the food processing, heat treatment of raw materials and storage of cooked and raw foods (Kacem et al., 2015). Antioxidants can delay or inhibit the oxidation of lipids or other molecules (Volf et al., 2013). The utilization of synthetic antioxidants is progressively restricted in the food industry because of their potential carcinogenicity.

\subsection{Absolute and Relative Liver Weight}

Relative liver weight is used as a possible indicator of changes in biochemical activity to maintain optimal functions due to many factors, including dietary constituents (Maronpot et al., 2010). In this study, we can observe from table (1) that the addition of PCM increased the relative liver weight significantly. This may be due to liver enlargement which is caused by its malfunction as a result of the drug intake. The addition of the plant lowered this enlargement significantly, as can be seen in Group 4.

\subsection{Lipid Peroxidation (MDA) Assay}

Lipids are considered a target for ROS which oxidizes them in a process called lipid peroxidation (Ayala et al., 2014). Malondialdehyde (MDA) is a secondary product of the lipid peroxidation process and it can be measured by TBARS assay (Esterbuer and Cheseman, 1990). The antioxidant effect of phenolic compounds is mainly due to their redox properties and their capacity to block the production of ROS. There are various possible mechanisms of this effect including free radical scavenging activity, transition metal chelating activity, and/or singlet-oxygen-quenching capacity (Rubió, Motilva, \& Romero, 2013).

Plants such as Ruta chalepensis L. are considered a valuable source of bioactive components such as natural antioxidants which possess defense mechanism against ROS (Ouerghemmi et al., 2017; Romojaro, Botella, Obón, $\&$ Pretel, 2013). Polyphenols constitute the main bioactive phytochemicals that have been proven effective in the prevention of certain chronic diseases such as coronary heart diseases, cancers and diabetes due to their free radical-scavenging activities (Lamien-Meda et al., 2008).

\subsection{Liver Function Tests}

The liver is the key organ in the regulation of homeostasis in the body. It is involved in almost all of the biochemical pathways related to growth, fight against disease, nutrient supply, energy provision and reproduction (Prabu, Kanchana, \& Sadiq, 2017). Excessive exposure to paracetamol can cause liver injury through the formation of a reactive metabolite that depletes hepatic glutathione and causes hepatocellular oxidative stress and damage (Cao et al., 2017). Paracetamol is one of the most popular analgesic and antipyretic drugs worldwide; however, its overdose is among the major causes of morbidity and mortality in its victims (Prabu et al., 2017). The present study shows that the common rue plant can significantly lower the ALT, AST and TBL blood levels which means that it can lower the hepatic injury. Elevated ALT and AST activities are considered a marker of hepatotoxicity; when the liver is injured, enzymes that are normally retained within its cells are released into the blood (Drotman \& Lawhorn, 1978). This release is caused by blister formation followed by degradation of 
phospholipids in the liver cell membrane which triggers tearing in the plasma membrane and consequently a release of AST and ALT into the bloodstream (Venkateswaran, Pari, Viswanathan, \& Menon, 1997). Most of the hepatotoxic chemicals damage liver cells mainly by inducing lipid peroxidation and other oxidative damage (Salwe, Mirunalini, Mano, \& Manimekalai, 2017).

In the toxified rats, we found that the addition of the plant reduced the TBL by half. This can be explained by the fact that PCM in a dose of $3 \mathrm{~g} / \mathrm{kg} \mathrm{BW}$ decreased the activity of both cytochrome $\mathrm{p} 450$ and bilirubin glucuronyltransferase, leading to the release of unconjugated bilirubin into the bloodstream (Davis, Ideo, Harrison, \& Williams, 1975). The significant reduction in liver function tests (ALT, AST and TBL), as compared with that of the positive control $(\mathrm{P}<0.05)$, maybe due to the high antioxidant activity of the plant.

The present study suggests that the traditional use of common rue maybe scientifically justified and that there is need for further investigations on its potential benefits. In addition, extending the experiment duration and giving the plant for longer period before giving the paracetamol dose could result in butter effect on blood lipid profile in hypercholesterolemic rats. Furthermore, it is possible that using plant extract instead of the dry plant in the in vivo study may give better result within shorter period of time.

\section{Conclusion}

It is concluded that the use of Ruta chalepensis L. plant significantly lowered hepatic toxicity as indicated by the liver enzyme levels. Also, the plant lowered the MDA level and liver weight. The ingestion of the plant can be significantly protective against hepatic injury.

\section{Acknowledgements}

The authors thank the Deanship of Scientific Research, at The University of Jordan for their financial support.

\section{References}

Abbas, M. A. (2017). Is the use of plants in Jordanian folk medicine for the treatment of male sexual dysfunction scientifically based? Review of in vitro and in vivo human and animal studies. Andrologia, 49(3), 1-21. https://doi.org/10.1111/and.12619

Afifi, F. U., \& Abu-Irmaileh, B. (2000). Herbal medicine in Jordan with special emphasis on less commonly used medicinal herbs. Journal of Ethnopharmacology, 72(1), 101-110. https://doi.org/10.1016/S0378-8741 (00)00215-4

Al-Qudah, M. A., Al-Sarayreh, S. A., Al-Tarawneh, I. N., Al-Shuneigat, J. M., Al-Saraireh, Y. M., \& Alsharafa, K. Y. (2015). The chemical composition and the antibacterial properties of Ruta graveolens essential oil grown in northern Jordan. Jordan Journal of Biological Sciences, 8(2), 139-143. https://doi.org/10.12816/002756

Atta, A. H., \& Alkofahi, A. (1998). Anti-nociceptive and anti-inflammatory effects of some Jordanian medicinal plant extracts. Journal of Ethnopharmacology, 60(2), 117-124. https://doi.org/10.1016/S0378-8741 (97)00137-2

Ayala, A., Muñoz, M. F., \& Argüelles, S. (2014). Lipid peroxidation: production, metabolism, and signaling mechanisms of malondialdehyde and 4-hydroxy-2-nonenal. Oxidative Medicine and Cellular Longevity, 2014, 1-31. https://doi.org/10.1155/2014/360438

Cao, L., Kwara, A., \& Greenblatt, D. J. (2017). Metabolic interactions between acetaminophen (paracetamol) and two flavonoids, luteolin and quercetin, through in - vitro inhibition studies. Journal of Pharmacy and Pharmacology, 69(12), 1762-1772. https://doi.org/10.1111/jphp.12812

Davis, M., Ideo, G., Harrison, N. G., \& Williams, R. (1975). Early inhibition of hepatic bilirubin conjugation after paracetamol (acetaminophen) administration in the rat. Digestion, 13(1-2), 42-48. https://doi.org/ $10.1159 / 000197694$

Dogan, Y., Ugulu, I., \& Durkan, N. (2013). Wild edible plants sold in the local markets of Izmir, Turkey. Pakistan Journal of Botany, 45(S1), 177-184.

Drotman, R. B., \& Lawhorn, G. T. (1978). Serum enzymes as indicators of chemically induced liver damage. Drug and Chemical Toxicology, 1(2), 163-171. https://doi.org/10.3109/01480547809034433

Esterbauer, H., \& Cheeseman, K. H. (1990). Determination of aldehydic lipid peroxidation products: malonaldehyde and 4-hydroxynonenal. Methods in Enzymology, 186, 407-421. https://doi.org/10.1016/ 0076-6879(90)86134-H 
Hinson, J. A., Reid, A. B., McCullough, S. S., \& James, L. P. (2004). Acetaminophen-induced hepatotoxicity: role of metabolic activation, reactive oxygen/nitrogen species, and mitochondrial permeability transition. Drug Metabolism Reviews, 36(3-4), 805-822. https://doi.org/10.1081/DMR-200033494

Ivanova, A., Mikhova, B., Najdenski, H., Tsvetkova, I., \& Kostova, I. (2005). Antimicrobial and cytotoxic activity of Ruta graveolens. Fitoterapia, 76(3), 344-347. https://doi.org/10.1016/j.fitote.2005.02.008

Kacem, M., Kacem, I., Simon, G., Mansour, A. B., Chaabouni, S., Elfeki, A., \& Bouaziz, M. (2015). Phytochemicals and biological activities of Ruta chalepensis L. growing in Tunisia. Food Bioscience, 12, 73-83. https://doi.org/10.1016/j.fbio.2015.08.001

Khouri, N. A., \& El-Akawi, Z. (2005). Antiandrogenic activity of Ruta graveolens L in male Albino rats with emphasis on sexual and aggressive behavior. Neuroendocrinology Letters, 26(6), 823-829.

Kong, Y. C., Lau, C. P., Wat, K. H., Ng, K. H., But, P. P. H., Cheng, K. F., \& Waterman, P. G. (1989). Antifertility principle of Ruta graveolens. Planta Medica, 55(2), 176-178. https://doi.org/10.1055/s-2006-961917

Lamien-Meda, A., Lamien, C. E., Compaoré, M. M., Meda, R. N., Kiendrebeogo, M., Zeba, B., \& Nacoulma, O. G. (2008). Polyphenol content and antioxidant activity of fourteen wild edible fruits from Burkina Faso. Molecules, 13(3), 581-594. https://doi.org/10.3390/molecules13030581

Limdi, J. K., \& Hyde, G. M. (2003). Evaluation of abnormal liver function tests. Postgraduate Medical Journal, 79(932), 307-312. https://doi.org/10.1136/pmj.79.932.307

Maronpot, R. R., Yoshizawa, K., Nyska, A., Harada, T., Flake, G., Mueller, G., \& Ward, J. M. (2010). Hepatic enzyme induction: Histopathology. Toxicologic Pathology, 38(5), 776-795. https://doi.org/10.1177/01926 23310373778

Nam, J., Lee, Y., Yang, Y., Jeong, S., Kim, W., Yoo, J. W., \& Jon, S. (2018). Is it worth expending energy to convert biliverdin into bilirubin? Free Radical Biology and Medicine, 124, 232-240. https://doi.org/ 10.1016/j.freeradbiomed.2018.06.010

Oran, S. A., \& Al-Isai, D. M. (2015). Medicinal plants in the high mountains of northern Jordan. International Journal of Biodiversity and Conservation, 6(6), 436-443. https://doi.org/10.5897/IJBC2014.0713

Ouerghemmi, I., Rebey, I. B., Rahali, F. Z., Bourgou, S., Pistelli, L., Ksouri, R., \& Tounsi, M. S. (2017). Antioxidant and antimicrobial phenolic compounds from extracts of cultivated and wild-grown Tunisian Ruta chalepensis. Journal of Food and Drug Analysis, 25(2), 350-359. https://doi.org/10.1016/j.jfda. 2016.04.001

Pandey, K. B., \& Rizvi, S. I. (2009). Plant polyphenols as dietary antioxidants in human health and disease. Oxidative Medicine and Cellular Longevity, 2(5), 270-278. https://doi.org/10.1016/j.jfda.2016.04.001

Pollock, N. R., Rolland, J. P., Kumar, S., Beattie, P. D., Jain, S., Noubary, F., \& Whitesides, G. M. (2012). A paper-based multiplexed transaminase test for low-cost, point-of-care liver function testing. Science Translational Medicine, 4(152), 152-129. https://doi.org/10.1126/scitranslmed.3003981

Prabu, K., Kanchana, N., \& Sadiq, A. M. (2017). Hepatoprotective effect of Eclipta alba on paracetamol induced liver toxicity in rats. Journal of Microbiology and Biotechnology Research, 1(3), 75-79.

Preethi, K. C., Kuttan, G., \& Kuttan, R. (2006). Anti-tumour activity of Ruta graveolens extract. Asian Pacific Journal of Cancer Prevention, 7(3), 439-443.

Raghav, S. K., Gupta, B., Agrawal, C., Goswami, K., \& Das, H. R. (2006). Anti-inflammatory effect of Ruta graveolens in murine macrophage cells. Journal of Ethnopharmacology, 104(1), 234-239. https://doi.org/ 10.1016/j.jep.2005.09.008

Reeves, P. G. (1997). Components of the AIN-93 diets as improvements in the AIN-76A diet. The Journal of Nutrition, 127(5), 838S-841S. https://doi.org/10.1093/jn/127.5.838S

Romojaro, A., Botella, M. Á., Obón, C., \& Pretel, M. T. (2013). Nutritional and antioxidant properties of wild edible plants and their use as potential ingredients in the modern diet. International Journal of Food Sciences and Nutrition, 64(8), 944-952. https://doi.org/10.3109/09637486.2013.821695

Rubió, L., Motilva, M. J., \& Romero, M. P. (2013). Recent advances in biologically active compounds in herbs and spices: a review of the most effective antioxidant and anti-inflammatory active principles. Critical Reviews in Food Science and Nutrition, 53(9), 943-953. https://doi.org/10.1080/10408398.2011.574802 
Salwe, K. J., Mirunalini, R., Mano, J., \& Manimekalai, K. (2017). Hepatoprotective and antioxidant activity of Murraya Koenigii leaves extract against paracetamol induced hepatotoxicity in Rats. International Journal of Basic and Clinical Pharmacology, 6(6), 1274-1281. https://doi.org/10.18203/2319-2003.ijbcp20172044

Singh, D., Cho, W. C., \& Upadhyay, G. (2016). Drug-induced liver toxicity and prevention by herbal antioxidants: an overview. Frontiers in Physiology, 6, 363-381. https://doi.org/10.3389/fphys.2015.00363

Terkmane, S., Gali, L., Bourrebaba, L., Shoji, K., Legembre, P., Konstantia, G., \& Bedjou, F. (2018). Chemical Composition, Antioxidant, and Anticancer Effect of Ruta chalepensis's Extracts against Human Leukemic Cells. Phytothérapie, 16(S1), S225-S236. https://doi.org/10.3166/phyto-2019-0153

Tsikas, D. (2017). Assessment of lipid peroxidation by measuring malondialdehyde (MDA) and relatives in biological samples: Analytical and biological challenges. Analytical Biochemistry, 524, 13-30. https://doi.org/10.1016/j.ab.2016.10.021

Venkateswaran, S., Pari, L., Viswanathan, P., \& Menon, V. P. (1997). Protective effect of Livex, a herbal formulation against erythromycin estolate induced hepatotoxicity in rats. Journal of Ethnopharmacology, 57(3), 161-167. https://doi.org/10.1016/S0378-8741(97)00062-7

Volf, I., Ignat, I., Neamtu, M., \& Popa, V. I. (2014). Thermal stability, antioxidant activity, and photo-oxidation of natural polyphenols. Chemical Papers, 68(1), 121-129. https://doi.org/10.2478/s11696-013-0417-6

Wang, L., Sun, J., Yi, Q., Wang, X., \& Ju, X. (2012). Protective effect of polyphenols extracts of adlay (Coix lachryma-jobi L. var. ma-yuen Stapf) on hypercholesterolemia-induced oxidative stress in rats. Molecules, 17(8), 8886-8897. https://doi.org/10.3390/molecules 17088886

Woreta, T. A., \& Alqahtani, S. A. (2014). Evaluation of abnormal liver tests. Medical Clinics, 98(1), 1-16. https://doi.org/10.1016/j.mcna.2013.09.005

\section{Copyrights}

Copyright for this article is retained by the author(s), with first publication rights granted to the journal.

This is an open-access article distributed under the terms and conditions of the Creative Commons Attribution license (http://creativecommons.org/licenses/by/4.0/). 